\title{
Orthopaedic Approaches to Proximal Humeral Fractures Following Trauma
}

\author{
Reza Mafi ${ }^{1}$, Wasim Khan ${ }^{2}$, Pouya Mafi ${ }^{3}$ and Sandip Hindocha ${ }^{*}, 4$ \\ ${ }^{I}$ Department of Orthopaedic Surgery, Diana Princess of Wales Hospital, Grimsby, DN33 2BA, UK \\ ${ }^{2}$ Royal National Orthopaedic Hospital, UK \\ ${ }^{3}$ Hull York Medical School, Heslington, York, YO10 5DD, UK \\ ${ }^{4}$ Department of Plastic Surgery, Whiston Hospital, Merseyside, L35 5DR, UK
}

\begin{abstract}
Proximal humeral fractures have been a topic of discussion in medical literature dating back as far as $3^{\text {rd }}$ century BC. Today, these fractures are the most common type of humeral fractures and account for about 5-6\% of all fractures in adults with the incidence rising rapidly with age. In broad terms the management of proximal humeral fractures can be divided into two categories: conservative versus surgical intervention. The aim of treatment is to stabilize the fracture, aid better union and reduce pain during the healing process. Failure to achieve this can result in impairment of function, and significantly weaken the muscles inserting onto the proximal humerus. With the rising incidence of proximal humeral fractures, especially among the elderly, the short and long term burden for patients as well as the wider society is increasing. Furthermore, there is a lack of consistency in the definitive treatment and management of displaced fractures. This systematic review of literature compares the surgical treatment of proximal humeral fractures with their conservative management, by evaluating the available randomised controlled trials on this topic.
\end{abstract}

Keywords: Bandages, conservative management, fractures, immobilisation, internal fixation, proximal humerus, randomised controlled trial, shoulder fracture, treatment outcome.

\section{BACKGROUND}

Proximal humeral fractures have been a topic of discussion in medical literature dating back as far as $3^{\text {rd }}$ century BC (1). For many centuries the mainstay of treatment in these fractures had been the Hippocratic doctrine: forceful reduction and bandaging followed by splinting (1). In the $19^{\text {th }}$ and $20^{\text {th }}$ century, notable advances were made in the management of these fractures with the introduction of sophisticated splinting techniques and internal fixation for displaced fractures [1]. Today, proximal humeral fractures are the most common type of humeral fractures [2-5] and account for about 5-6\% of all fractures in adults [6]. The prevalence is highest in the elderly population and the incidence rises markedly with age [6], with highest prevalence in those aged 70 years and over [7-9]. These fractures are about 3 times more common in women than men $[10,11]$ and the majority (about 90\%) are as a result of falls from standing height [12]. Patients with poor bone quality [2] and osteoporosis are those at highest risk of sustaining this type of fracture. In fact, a study of the Finish population by Palvanen [13], showed that the incidence of proximal humeral fractures related to osteoporosis had tripled in number between 1970 and 2002. The majority of proximal humeral fractures are closed fractures meaning that

*Address correspondence to this author at the Department of Plastic Surgery, Whiston Hospital, Liverpool, UK L35 5DR, UK;

Tel: + 44(0)1244366265; Fax: +44(0)1244366265;

E-mail: hindocha2001@yahoo.com there is no laceration of the overlying skin by the fracture of humerus [14]. It has been reported that about a fifth of all proximal humerus fractures require a surgical intervention [15].

\section{CLASSIFICATION}

\section{Neer's Classification}

Charles Neer's classification of the proximal humeral fractures in 1970 is the most widely used system for classifying these fractures [16]. The essence of this method of classification is based on the anatomical concepts described by Codman in the 1930s [17]. The proximal humerus subdivided into four segments 1) the humeral head superior to the anatomical neck 2) greater tuberosity 3) lesser tuberosity 4) humeral shaft. Neer argued that these parts can be affected by fracture lines, however, will be considered as a significant displacement if the segment has moved more than $10 \mathrm{~mm}$, or is at an angle of 45 degrees or more in relation to the rest of the segments or the humerus. Therefore, a fractured lesser tuberosity that does not meet the above criteria, is classified as an undisplaced fracture i.e. one-part fracture according to Neer's method. A considerable number of proximal humeral fractures are undisplaced fractures. Despite the common reference to Neer that $85 \%$ of all proximal humeral fractures are undisplaced [18], a recent prospective study showed that the figure could be closer to around 50\% [7]. Depending on the number of fracture lines present, the fracture can be subdivided into two, three or four part fractures. Each of these fractures, 
whether displaced or undisplaced can be accompanied by an anterior or posterior gleno-humeral joint dislocation, however this has been shown to be associated with a low rate of inter and intra observer reliability [19]. At times even with sophisticated imaging techniques, it may be difficult to access the fracture pattern at first presentation. This classification is not correlated with the extent to which the humeral blood supply may be affected following a fracture.

\section{AO Classification}

Muller in 1991, proposed another widely used classification method, the AO classification [20] which has been updated with the OTA association in 2007 [21]. Taking into account the importance of the blood supply this classification describes proximal humeral fractures in relation to the anatomical neck of the humerus i.e. distal or proximal. The blood supply of the proximal humerus resembles that of the proximal femur and can lead to avascular necrosis of the humeral head if compromised. The blood supply of the humeral head is mainly through the arcuate artery which comes from the ascending branch of anterior humeral circumflex artery. Its entrance into the humerus is marked by the intertubercular groove and branches off to supply the lesser and greater tuberosities and perfuses the entire epiphysis of the humeral head. If the arcuate artery was resected, the blood supply to the humeral head cannot be maintained through alternative routes such as the posterior humeral circumflex artery. This would lead to avascular necrosis. In this classification three different fracture types are introduced: Type A, B and C. Type A fractures are extra articular, unifocal, Type B extra articular bifocal and Type $\mathrm{C}$ intra articular [22].

\section{Interventions}

In broad terms, the management of proximal humeral fractures can be divided into two categories: conservative versus surgical intervention. Conservative management of the proximal humeral fractures involves immobilisation of the arm followed by encouraging early mobilisation through exercise and physiotherapy. This approach is generally used for undisplaced fractures, stable fractures, minimally displaced fractures, and at times even for some displaced fractures. Surgical interventions, on the other hand, are reserved for more complicated, displaced and unstable fractures. These can be summed up as:

\section{- $\quad$ External fixation \\ - Closed reduction and percutaneous pinning \\ - $\quad$ Open reduction and plating \\ - Open reduction and tension-band fixation \\ - $\quad$ Anterograde/ retrograde intermedullary nailing \\ - Hemiarthroplasty \\ - Total shoulder replacement}

Close reduction is performed with either percutaneous pinning or K-wires. Hemiarthroplasty refers to replacement of humeral head in contrast to total shoulder replacement where both the humeral head and the glenoid are replaced using a procedure known as reverse polarity arthroplasty. In this approach the configuration of humeral head (ball) and glenoid (socket) is reversed in that the glenoid is replaced by a ball and humeral head becomes the socket.

The management following surgical intervention involves immobilisation followed by exercise and physiotherapy.

\section{The Benefit of Interventions}

The purpose of immobilisation is to stabilise the fracture, aid better union and reduce pain during the healing process. Failure to achieve fracture union can result in impairment of function, and significantly weaken the muscles inserting onto the proximal humerus. However there are risks associated with immobilisation, especially if it is done for an extended period of time, such as pain, stiffness and significant reduction in function. The post-operative management aims to reduce or even prevent these complications, through encouraging early use of the arm, together with gentle exercise and physiotherapy. Surgery aims to stabilise the fracture and allow restoration of the joint. Once the fracture has been reduced and is stable, this will allow earlier mobilisation of both the shoulder and elbow joints. This can in turn help reduce post-operative complications such as pain, stiffness, muscle weakness or reduced functional ability. It is important to realise that there are many factors that affect the surgical outcome of the proximal humeral fractures. Factors such as patient's age, bone quality, mobility and frailty determine the choice of intervention, length of rehabilitation and recovery time, both following trauma and further management.

\section{The Purpose of this Review}

With the rising incidence of proximal humeral fractures, especially among the elderly, the short and long term burden for patients as well as the wider society is increasing [13]. Furthermore, there is lack of consistency in the definitive treatment and management of displaced fractures [23] and recovery [24]. The purpose of this review is to compare the available randomised controlled trials in the management of proximal humeral fractures, with the intension of finding evidence whether surgical intervention is preferred to conservative treatment.

\section{Methodology}

The randomised controlled trials were searched using the electronic databases Medline, CINAHL (EBSCO), ZETOC, PubMed, EMBASE, AMED, PREMEDLINE In-Process \& Non-Indexed Citations (OvidSP), ASSIA (CSA Illumina), Conference Proceedings Citation Index: Science (ISI) on Web of Knowledge, PsycINFO (OvidSP), Science Citation Index (ISI) on Web of Knowledge, Social Sciences Citation Index (ISI) on Web of Knowledge and Cochrane Library (Wiley). The following keywords were used to cite relevant articles: fractures, proximal humerus, randomised controlled trial, internal fixation, conservative management, shoulder fracture, treatment outcome, immobilisation, bandages

All available randomise controlled trials comparing the surgical management of proximal humeral fractures with conservative non-surgical approach, were included in this review.

Studies were excluded which 1) did not include conservative management of proximal humeral fractures 
2) did not comment on the functional outcome 3) were not randomise 4) were not available for free viewing. A total of 17 articles were reviewed. 6 articles were identified as relevant according to the inclusion criteria. methods of treatment compared were closed manipulation, versus transcutaneous reduction and external fixation. At 12 months follow up, they concluded that external fixation produced more favourable results in terms of regaining

\section{RESULT}

\begin{tabular}{|c|c|c|c|c|}
\hline Author & Patient cohort & Intervention & Follow-up & Relevant outcome \\
\hline Stableforth 1984 [25] & $\begin{array}{l}\text { Bristol, UK } \\
32 \text { patients with displaced 4- } \\
\text { part proximal humeral } \\
\text { fractures (Neer). }\end{array}$ & $\begin{array}{l}\text { Hemi-arthroplasty versus } \\
\text { closed manipulation and } \\
\text { sling }\end{array}$ & 6 months & $\begin{array}{c}\text { Dependent in activities of daily living } \\
\text { Range of motion (flexion, medial rotation, } \\
\text { lateral rotation) } \\
\text { Pain } \\
\text { Muscle strength (flexion, abduction, lateral } \\
\text { rotation) }\end{array}$ \\
\hline Kristiansen 1988 [26] & $\begin{array}{l}\text { Copenhagen, Denmark } \\
30 \text { patients with } 31 \text { displaced } \\
\text { 2-, 3- and 4-part proximal } \\
\text { humeral fractures (Neer). }\end{array}$ & $\begin{array}{l}\text { Percutaneous reduction } \\
\text { and external fixation } \\
\text { versus closed } \\
\text { manipulation and sling }\end{array}$ & 2 years & $\begin{array}{c}\text { Quality of fracture reduction: good, fair, } \\
\text { poor } \\
\text { Functional overall score: excellent, } \\
\text { satisfactory, unsatisfactory, poor. }\end{array}$ \\
\hline Zyto 1997 [27] & $\begin{array}{c}\text { Stockholm, Sweden } \\
40 \text { patients with displaced 3- or } \\
\text { 4-part fractures (Neer). }\end{array}$ & $\begin{array}{l}\text { Internal fixation using } \\
\text { surgical tension band or } \\
\text { cerclage wiring versus } \\
\text { sling }\end{array}$ & 50 months & $\begin{array}{l}\text { Subjective assessment of function including } \\
\text { ability to carry } 5 \mathrm{~kg} \text {, sleep on injured side, } \\
\text { comb hair, perform personal hygiene }\end{array}$ \\
\hline Fjalestad 2010 [28] & $\begin{array}{l}\text { Oslo, Norway } \\
50 \text { patients with displaced } \\
\text { 3-part and 4-part fractures }\end{array}$ & $\begin{array}{l}\text { Open reduction and } \\
\text { fixation with an } \\
\text { interlocking plate device } \\
\text { versus immobilisation } \\
\text { with modified Velpeau } \\
\text { bandage }\end{array}$ & 2 years & $\begin{array}{c}\text { Constant shoulder score } \\
\text { ASES questionnaire } \\
\text { Quality of life score } \\
\text { subsequent operation } \\
\text { Radiographic outcomes Health economic }\end{array}$ \\
\hline Olerud 2011a [29] & $\begin{array}{l}\text { Stockholm, Sweden } \\
60 \text { patients with displaced 3- } \\
\text { part proximal humeral } \\
\text { fractures }\end{array}$ & $\begin{array}{l}\text { open reduction and } \\
\text { fixation with a PHILOS } \\
\text { plate versus conservative } \\
\text { treatment with } \\
\text { immobilisation in a sling }\end{array}$ & 2 years & $\begin{array}{c}\text { Constant shoulder score } \\
\text { DASH [Disabilities of the Arm, Shoulder } \\
\text { and Hand) questionnaire Quality of life } \\
\text { score: EQ-5D }\end{array}$ \\
\hline Olerud 2011b [30] & $\begin{array}{l}\text { Stockholm, Sweden } \\
55 \text { patients with displaced 4- } \\
\text { part proximal humeral } \\
\text { fractures }\end{array}$ & $\begin{array}{l}\text { Hemiarthroplasty } \\
\text { versus conservative } \\
\text { treatment with arm } \\
\text { immobilisation } \\
\text { in a sling }\end{array}$ & 2 years & $\begin{array}{c}\text { Constant shoulder score (both shoulders) } \\
\text { DASH questionnaire } \\
\text { Quality of life score: EQ-5D }\end{array}$ \\
\hline
\end{tabular}

\section{DISCUSSION}

Fjalstadt [28] included 50 patients aged 60 years and over with severe displaced 3- and 4-part fracture. 25 patients were randomly allocated to conservative treatment and the other 25 had angular stable interlocking implants. They reported that at 12 months follow up there was no significant difference in the QALYs between the two groups (mean difference in number of QALYs $=0.027$ Confidence Interval $(\mathrm{CI})=-0.025,0.078)$.

However, there are several limitations associated with this trial, the first being the short follow up period. There are however several limitations associated with this trial. The first is the short follow up period. It is important to assess long term follow up to obtain thorough results in relation to the effect of treatment [31]. Although it has been reported that 12 month follow up is adequate in assessing the outcome of ORIF approach [32], it should be noted that the possible development of avascular necrosis of humeral head is likely to impact QALYs. Another limitation of this study is the small sample size.

Kristiansen [26] compared the functional outcome and quality of fracture reduction in 30 patients, with 31 displaced 2-, 3-, and 4-part proximal humeral fracture. The two function, safer healing and better reduction. The quality of reduction was judged by post-operative radiography. Functional results were assessed as being excellent, satisfactory, unsatisfactory or poor according to Neer [16] scoring system, although they excluded the anatomical score.

Zyto [27] randomised 40 patients with a mean age of 74 years into two different intervention arms, comparing conservative treatment with tension-band osteosynthesis. All patients had displaced 3- or 4-part fracture of proximal humerus. They reported that the optimal functional ability was regained within the first 12 months, although the follow up period of the participants lasted up to 5 years. The main complications noted were among the surgical cohort. Despite the improved positioning and reduction in the patients treated surgically, the functional outcome as measured by the subjective assessment of function at 12 months and at final follow up was not different between the two groups.

Stableforth [25] randomly allocated a total of 32 participants with 4-part fracture into either hemoarthroplasty intervention or closed manipulation and sling. The surgical group made a better functional recovery. This was assessed by being independent for activities of daily living at 6 months, pain score and power in flexion, 
abduction and lateral rotation. The hemi-arthroplasty group scored higher in all categories, although there is no statistical analysis showing that the difference in the functional outcome between the two groups is actually significant. He concluded that the closed manipulation did not result in a satisfactory outcome due to the severe soft tissue injury associated with the fractures and the detachment of the humeral head.

Olerud et al. [29] in their study of 60 participants with displaced 3-part fracture, included patients sustaining lowenergy trauma with no history of previous shoulder problems. Furthermore, all participants were living independently and were not institutionalised prior to sustaining the fracture. They found that the functional outcome according to DASH and HRQol was better in the locking plate group compared to the non-surgical group. Despite this, $13 \%$ of the surgical patients had some form of severe complication which required a major re-operation. In addition to these, $17 \%$ of the locking plate patients required a second intervention in form of a minor surgical operation. They concluded that considering the risk of the surgical intervention, conservative treatment is probably the treatment of choice for the majority of elderly patients with lower functional demands. They report a potential limitation of their study being the lack of power in the comparison of randomised groups. There is also an element of recall bias due to the fact that the interpretation of quality of life data, is based on the participants' ability to recall their health state prior to sustaining the fracture.

Olerud et al. [30] reported on the outcome of their 2 year randomised controlled trial of 55 participants with displaced 4-part fracture of the proximal humerus, treated with either conservatively or with hemi-arthroplasty. At 2 year followup the health-related quality of life according to the EQ-5D was significantly better in the Hemi-arthroplasty group. The results of DASH and pain assessment score were both in favour of hemi-arthroplasty. There was no difference in the range of motion between the groups.

\section{CONCLUSION}

Overall due to the mixed outcomes reported in the randomised controlled studies included in this systematic review of literature, it is hard to draw a clear cut conclusion as to which intervention is most favourable, for the treatment of proximal humeral fractures. These trials are small in terms of patient cohort and follow up period. We have concluded that there is lack of adequate evidence to suggest that surgical intervention is preferable to conservative treatment of proximal humeral fractures.

\section{CONFLICT OF INTEREST}

The authors confirm that this article content has no conflict of interest.

\section{ACKNOWLEDGEMENTS}

Declared none.

\section{REFERENCES}

[1] Brorson S. Management of proximal humeral fractures in the nineteenth century: an historical review of preradiographic sources. Clin Orthop Relat Res 2011; 469(4): 1197-206.
[2] Aaron D, Shatsky J, Paredes JC, Jiang C, Parsons BO, Flatow EL. Proximal humeral fractures: internal fixation. J Bone Joint Surg Am 2012; 94(24): 2280-8.

[3] Robinson CM, Amin AK, Godley KC, Murray IR, White TO. Modern perspectives of open reduction and plate fixation of proximal humerus fractures. J Orthop Trauma 2011; 25(10): 61829.

[4] Murray IR, Amin AK, White TO, Robinson CM. Proximal humeral fractures: current concepts in classification, treatment and outcomes. J Bone Joint Surg Br 2011; 93(1): 1-11.

[5] Egol KA, Koval KJ, Zuckerman JD. Handbook of Fractures. 4 ed. Philadelphia: Wolters Kluwer/Lippincott Williams, 2010.

[6] Court-Brown CM, Caesar B. Epidemiology of adult fractures: A review. Injury 2006; 37(8): 691-7.

[7] Court-Brown CM, Garg A, McQueen MM. The epidemiology of proximal humeral fractures. Acta Orthop Scand 2001; 72(4): 36571.

[8] Kannus P, Palvanen M, Niemi S, Parkkari J, Jarvinen M, Vuori I. Osteoporotic fractures of the proximal humerus in elderly Finnish persons: sharp increase in 1970-1998 and alarming projections for the new millennium. Acta Orthop Scand 2000; 71(5): 465-70.

[9] Bengner U, Johnell O, Redlund-Johnell I. Changes in the incidence of fracture of the upper end of the humerus during a 30-year period. A study of 2125 fractures. Clin Orthop Relat Res 1988(231): 17982.

[10] Resch H. Proximal humeral fractures: current controversies. J Shoulder Elbow Surg 2011; 20(5): 827-32.

[11] Lind T, Kroner K, Jensen J. The epidemiology of fractures of the proximal humerus. Arch Orthop Trauma Surg 1989; 108(5): 285-7.

Horak J, Nilsson BE. Epidemiology of fracture of the upper end of the humerus. Clin Orthop Relat Res 1975; (112): 250-3.

[13] Alvanen M, Kannus P, Niemi S, Parkkari J. Update in the epidemiology of proximal humeral fractures. Clin Orthop Relat Res 2006; 442: 87-92.

[14] Handoll HH, Ollivere BJ, Rollins KE. Interventions for treating proximal humeral fractures in adults. Cochrane Database Syst Rev 2012; 12: Cd000434.

[15] Maravic M, Le Bihan C, Landais P, Fardellone P. Incidence and cost of osteoporotic fractures in France during 2001. A methodological approach by the national hospital database. Osteoporos Int 2005; 16(12): 1475-80.

[16] Neer CS, $2^{\text {nd }}$. Displaced proximal humeral fractures. I. Classification and evaluation. J Bone Joint Surg Am 1970; 52(6): 1077-89.

[17] Codman A. The Shoulder. Boston, Massachusetts: Thomas Todd; 1934.

[18] Koval KJ, Gallagher MA, Marsicano JG, Cuomo F, McShinawy A, Zuckerman JD. Functional outcome after minimally displaced fractures of the proximal part of the humerus. J Bone Joint Surg Am 1997; 79(2): 203-7.

[19] Sidor ML, Zuckerman JD, Lyon T, Koval K, Cuomo F, Schoenberg N. The Neer classification system for proximal humeral fractures. An assessment of interobserver reliability and intraobserver reproducibility. J Bone Joint Surg Am 1993; 75(12): 1745-50

[20] Muller ME, Allgöwer M, Schneider R, Willenegger H. Manual of internal fixation: techniques recommended by the AO-ASIF Group. $3^{\text {rd }}$ ed. Berlin: Springer-Verlag 1991.

[21] Marsh JL, Slongo TF, Agel J, et al. Fracture and dislocation classification compendium-2007: Orthopaedic Trauma Association classification, database and outcomes committee. J Orthop Trauma 2007; 21(10 Suppl): S1-133

[22] Robinson BC, Athwal GS, Sanchez-Sotelo J, Rispoli DM. Classification and imaging of proximal humerus fractures. Orthop Clin North Am 2008; 39(4): 393-403.

[23] Guy P, Slobogean GP, McCormack RG. Treatment preferences for displaced three- and four-part proximal humerus fractures. J Orthop Trauma 2010; 24(4): 250-4.

[24] Hodgson S. Proximal humerus fracture rehabilitation. Clin Orthop Relat Res 2006; 442: 131-8.

[25] Stableforth PG. Four-part fractures of the neck of the humerus. J Bone Joint Surg Br 1984; 66(1): 104-8.

[26] Kristiansen B, Kofoed H. Transcutaneous reduction and external fixation of displaced fractures of the proximal humerus. A controlled clinical trial. J Bone Joint Surg Br 1988; 70(5): 821-4. 
[27] Zyto K, Ahrengart L, Sperber A, Tornkvist H. Treatment of displaced proximal humeral fractures in elderly patients. J Bone Joint Surg Br 1997; 79(3): 412-7.

[28] Fjalestad T, Hole MO, Jorgensen JJ, Stromsoe K, Kristiansen IS. Health and cost consequences of surgical versus conservative treatment for a comminuted proximal humeral fracture in elderly patients. Injury 2010; 41(6): 599-605.

[29] Olerud P, Ahrengart L, Ponzer S, Saving J, Tidermark J. Internal fixation versus nonoperative treatment of displaced 3-part proximal humeral fractures in elderly patients: a randomized controlled trial. J Shoulder Elbow Surg 2011; 20(5): 747-55.
[30] Olerud P, Ahrengart L, Ponzer S, Saving J, Tidermark J. Hemiarthroplasty versus nonoperative treatment of displaced 4-part proximal humeral fractures in elderly patients: a randomized controlled trial. J Shoulder Elbow Surg 2011; 20(7): 1025-33.

[31] Glick H, Doshi JA, Sonnad SS, Polsky D. Economic evaluation in clinical trials. Oxford: Oxford University Press 2010.

[32] Olsson C, Nordquist A, Petersson CJ. Long-term outcome of a proximal humerus fracture predicted after 1 year: a 13-year prospective population-based follow-up study of 47 patients. Acta orthop 2005; 76(3): 397-402.

(C) Mafi et al.; Licensee Bentham Open.

This is an open access article licensed under the terms of the Creative Commons Attribution Non-Commercial License (http://creativecommons.org/licenses/by-nc/3.0/) which permits unrestricted, non-commercial use, distribution and reproduction in any medium, provided the work is properly cited. 